\title{
POLUIÇÃO POR MERCÚRIO EM ATERROS URBANOS DO PERÍODO COLONIAL NO EXTREMO SUL DO BRASIL
}

\author{
Luiz Paulo de Moura Fragomeni* e Ari Roisenberg \\ Instituto de Geociências, Universidade Federal do Rio Grande do Sul, CP 15001, 91501-970 Porto Alegre - RS, Brasil \\ Nicolai Mirlean \\ Instituto de Oceanografia, Fundação Universidade de Rio Grande, CP 474, 96200-900 Rio Grande - RS, Brasil
}

Recebido em 5/5/09; aceito em 21/4/10; publicado na web em 20/7/10

\begin{abstract}
MERCURY POLLUTION IN LAND RECLAMATION FILLS FROM THE COLONIAL PERIOD OF THE BRAZIL'S SOUTHERNMOST. Land reclamation fills in the city of Rio Grande (RS) are polluted by mercury with concentrations ranging from 0.3 to $18.7 \mathrm{mg} \mathrm{kg}^{-1}$. The level of $\mathrm{Hg}$ pollution decreases from the oldest landfills of $18^{\text {th }}$ century to recent ones. Mercury distribution along vertical profiles resembles the same for copper, lead, and zinc, what allow supposing that mercury distribution has an autochthonous character. It is suggested that the principal source of mercury pollution was the activities related to animal skin and fair hair treatment, using ancient technology known as "carroting". Similar scenario of environmental risk could be met in other Brazilian cities with similar colonization history.
\end{abstract}

Keywords: mercury; metal soil pollution; urban pollution.

\section{INTRODUÇÃO}

A exposição humana ao mercúrio e seus compostos, através da ingestão de alimentos ou do contato com vapores, causa severos efeitos no sistema neurológico, afetando, ainda, os tratos gastrointestinal e urinário. ${ }^{1,2}$

Valores acima dos padrões aceitos para mercúrio em solos significam a potencial poluição ou contaminação de vários meios (água superficial, água subterrânea, biota) e o próprio solo que, em algumas situações, pode ser considerado como fonte de poluição. As fontes de poluição por mercúrio são numerosas, entre as quais os resíduos industriais e de mineração são importantes. ${ }^{3}$ São conhecidos exemplos extremos de poluição por mercúrio em solos urbanos no mundo, ${ }^{4,5}$ sendo que, na maioria dos casos, as fontes desta poluição são facilmente identificáveis, o que permite a tomada de medidas corretivas para seu controle. Situações mais graves são aquelas em que a urbanização já ocupou área historicamente contaminada, onde a erradicação da contaminação dos solos urbanos não é prática. Nestes casos, a reestruturação urbana, através da realocação dos seus elementos, pode ser a única medida possível a ser tomada.

No Brasil têm sido estudados e apresentados casos de poluição de solos por mercúrio, principalmente associados a atividades industriais recentes e de garimpagem. ${ }^{6,7} \mathrm{O}$ desenvolvimento industrial no Brasil ocorreu concomitante com sua urbanização, tornando-se comum a absorção de antigas áreas industriais por zonas residenciais. Desta forma, é de se esperar que algumas populações se encontrem assentadas em áreas poluídas por antigas atividades industriais não controladas.

A cidade do Rio Grande é um pólo portuário e industrial no extremo sul do Brasil, que começou seu desenvolvimento há mais de 200 anos. Em condições de falta de território (a cidade foi instalada numa estreita península), as zonas portuária, industrial e urbana foram posicionadas muito próximas. Com o crescimento da cidade, acompanhado de aterramento de baixios e áreas aquáticas rasas, a zona residencial cercou e avançou sobre as industriais.

As primeiras informações sobre a existência da poluição por mercúrio no Município de Rio Grande apareceram como o resultado do estudo da composição dos sedimentos no canal da navegação do

\footnotetext{
*e-mail: lpfragomeni@terra.com.br
}

porto de Rio Grande. ${ }^{8}$ Estudos posteriores revelaram que os solos da cidade são a fonte principal da poluição dos sedimentos do estuário, ${ }^{9,10}$ e que a anomalia de mercúrio na camada superficial do solo ocupa cerca de $30 \%$ da parte central (mais antiga) da cidade.

O presente estudo teve como alvo a discussão da história da poluição por mercúrio na cidade de Rio Grande, através da distribuição deste elemento nos depósitos urbanos, e entender as fontes desta poluição.

\section{PARTE EXPERIMENTAL}

\section{Área de estudo e amostragem}

A cidade de Rio Grande está localizada na planície costeira do Rio

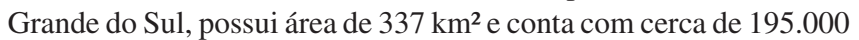
habitantes. ${ }^{11}$ A cidade é considerada a mais antiga do Rio Grande do Sul e a ocupação de seu território data de $1735 .{ }^{12,13}$ Encontra-se instalada em local de terras baixas e alagáveis, motivo que levou à construção de aterros logo nos primeiros anos de colonização, com o intuito de elevar o nível dos terrenos e de geração de solo. Em mais de 250 anos de crescimento urbano, o solo criado foi gradualmente invadindo áreas alagadas e alagáveis, dando lugar a fortificações, áreas portuárias, terrenos urbanos e industriais, até resultar na configuração atual (Figura 1S, material suplementar). ${ }^{10}$

As praças da cidade constituem-se nos raros espaços poupados pelas edificações do espaço urbano. Formam áreas historicamente abertas e foram, portanto, eleitas como locais para coleta de amostras. Foram coletadas amostras na Praça Sete de Setembro (ponto 1), cujo aterro data da primeira metade do século 18; na Praça Xavier Ferreira (ponto 2) e na Praça Tamandaré (ponto 3), com aterros que datam do início e do final do século 19, respectivamente, e, finalmente, foi coletada amostra em aterro urbano em terreno de propriedade particular (ponto 4) que data da segunda metade do século 20 (Figura $1 \mathrm{~S}$, material suplementar). Todos os aterros apresentaram proporções variadas de inclusões, misturadas ao sedimento arenoso utilizado em sua execução. Estas inclusões constituídas de materiais produzidos nas épocas de construção dos aterros compreendem resíduos diversos, lixo e entulho e são utilizadas como ferramenta na sua datação. ${ }^{10}$

As amostras foram coletadas com a utilização de trado de aço inoxidável a cada $5 \mathrm{~cm}$ do perfil dos aterros, desde a superfície até o 
nível de lençol freático, armazenadas em sacos plásticos, rotuladas e hermeticamente fechadas.

\section{Tratamento das amostras e análise}

No laboratório, as amostras foram secas à temperatura de $25^{\circ} \mathrm{C}$, desgrumadas e peneiradas com a utilização de rede de nylon com malha de 0,2 mm. Com o objetivo de otimizar a efetividade das extrações, a alíquota da amostra peneirada foi pulverizada em gral de ágata e armazenada em recipientes de vidro com tampa. ${ }^{14}$

A digestão das amostras pulverizadas para detecção do mercúrio total foi realizada com base na metodologia USEPA 7471. ${ }^{15} \mathrm{Cada}$ amostra $(0,2 \mathrm{~g})$ foi colocada em frasco volumétrico de $100 \mathrm{~mL}$, no qual foram adicionados $15 \mathrm{~mL}$ de "água régia", sendo aquecido durante 2 min em temperaturas de até $95^{\circ} \mathrm{C}$. Após, o frasco foi resfriado, adicionado de $15 \mathrm{~mL}$ de permanganato de potássio e colocado em banho quente por $30 \mathrm{~min}$, em temperaturas de até $95^{\circ} \mathrm{C}$. Após o resfriamento, foram adicionados $6 \mathrm{~mL}$ de cloreto hidroxilamina de sódio para reduzir o excesso de permanganato de potássio. A suspensão final foi filtrada e o volume do filtrado completado até 100 $\mathrm{mL}$ com água Milli-Q.

Para análise de $\mathrm{Cu}, \mathrm{Ni}, \mathrm{Pb}$, e $\mathrm{Zn}$ as amostras de solo (fração <0,2 $\mathrm{mm}$ ) foram submetidas à digestão química, com sucessivos ataques a quente de $\mathrm{HNO}_{3}, \mathrm{H}_{2} \mathrm{O}_{2}$ e $\mathrm{HCl}$, conforme o método USEPA 3050b. ${ }^{16}$

O mercúrio total foi determinado através da técnica de espectrografia de absorção atômica por vapor frio - CVAAS, no equipamento AAS GBC 932AA. A sensibilidade do método analítico (limite de detecção) é $0,2 \mu \mathrm{g} \mathrm{L}^{-1}$. O limite de detecção (LD) é definido como a concentração do analito que produz um sinal que excede em três vezes o desvio padrão do sinal ao passar o branco. ${ }^{17}$ Cada amostra foi analisada em triplicata e o valor médio foi calculado. O valor máximo de desvio padrão relativo (RSD) de cada amostra foi menor que $4 \%$. A exatidão de análise do $\mathrm{Hg}$ foi controlada através de análise paralela de amostras certificadas (PACS-2 e MESS-3, amostras de referência de sedimentos do National Research Council, Canadá). ${ }^{18} \mathrm{O}$ valor certificado do $\mathrm{Hg}$ para MESS-3 é 0,091 $\pm 0,009 \mathrm{mg} \mathrm{kg}^{-1}$ (recuperado neste estudo - 0,092 $\pm 0,001 ; 10$ réplicas), e para PACS-2 - 3,04 \pm $0,20 \mathrm{mg} \mathrm{kg}^{-1}$ (recuperado neste estudo - $3,06 \pm 0,16 ; 10$ réplicas).

As concentrações dos metais $\mathrm{Pb}, \mathrm{Cu}, \mathrm{Zn}$ e Ni foram determinadas por espectrofotometria de absorção atômica por chama, utilizando-se o equipamento GBC 932AA. A exatidão da análise foi aprovada pela análise paralela de amostra de referência MESS-3 (NRC Canadá). ${ }^{18}$ A análise demonstrou boa recuperação dos valores de referência, na faixa de $95 \%$ em 10 réplicas ( $\mathrm{Pb}$ certificado $21,1 \pm 0,7 \mathrm{mg} \mathrm{kg}^{-1}$, recuperado 20,6 \pm 0,5 $\mathrm{mg} \mathrm{kg}^{-1}$; Cu certificado 33,9 $\pm 1,6 \mathrm{mg} \mathrm{kg}^{-1}$, recuperado $34,8 \pm 1,2 \mathrm{mg} \mathrm{kg}^{-1} ; \mathrm{Zn} 159 \pm 8 \mathrm{mg} \mathrm{kg}^{-1}$, recuperado 153 $\pm 5 \mathrm{mg} \mathrm{kg}^{-1}$; Ni 46,9 $\pm 2,2 \mathrm{mg} \mathrm{kg}^{-1}$, recuperado $47,3 \pm 1,5 \mathrm{mg} \mathrm{kg}^{-1}$. Todas as medidas de amostras de solo foram feitas em 3 réplicas com desvio padrão relativo menor que $5 \%$.

\section{RESULTADOS}

Na Tabela 1 observa-se uma tendência de menor concentração média de $\mathrm{Hg}$ em aterros mais recentes, entretanto, a presença de valores ainda relativamente elevados no aterro mais recente (ponto 4) indica que, ainda nos dias atuais, há continuidade do processo de redistribuição da poluição por mercúrio na cidade. $\mathrm{O}$ processo de redistribuição é alimentado pela contínua mobilização de solo (chuva, vento, limpeza urbana, entulho e lixo) originado nos aterros poluídos e utilizado como material de construção para os aterros mais recentes. $\mathrm{O}$ aterro do ponto 4 foi construído com entulho, lixo urbano e resíduos de varrição de ruas da cidade de Rio Grande; a periódica varrição urbana de locais historicamente poluídos pode ter contribuído com poeira e solos superficiais contaminados, que resultaram em concentrações localmente elevadas nos locais de disposição.

Tabela 1. Concentração do mercúrio $\left(\mathrm{mg} \mathrm{kg}^{-1}\right)$ em aterros de Rio Grande

\begin{tabular}{|c|c|c|c|c|c|}
\hline $\begin{array}{l}\text { Ponto } \\
\text { (prof.) }\end{array}$ & Descrição & $\begin{array}{l}\text { Data de } \\
\text { execução do } \\
\text { aterro }\end{array}$ & mínimo & máximo & $\begin{array}{c}\text { média } \pm \\
\text { DP }\end{array}$ \\
\hline $\begin{array}{l}1 \\
(0 \text { a 135) }\end{array}$ & $\begin{array}{l}\text { Praça Sete } \\
\text { de Setembro }\end{array}$ & Séc. 18 & 1,3 & 18,7 & $6,7 \pm 5,6$ \\
\hline $\begin{array}{l}2 \\
(0 \text { a } 120)\end{array}$ & $\begin{array}{c}\text { Praça Xavier } \\
\text { Ferreira }\end{array}$ & Séc. 19 início & 0,8 & 18,3 & $3,1 \pm 3,4$ \\
\hline $\begin{array}{l}3 \\
(0 \text { a } 65)\end{array}$ & Praça Tamandaré & Séc. 19 final & 0,3 & 7,0 & $2,7 \pm 2,4$ \\
\hline $\begin{array}{l}4 \\
(0 \text { a } 60)\end{array}$ & Aterro particular & Séc. 20 final & 0,6 & 3,5 & $2,2 \pm 1,0$ \\
\hline \multirow{2}{*}{\multicolumn{2}{|c|}{$\begin{array}{l}\text { Referência de qualidade da } \\
\text { CETESB }(2005)^{22}\end{array}$}} & \multicolumn{2}{|c|}{ Uso agrícola } & \multicolumn{2}{|r|}{12} \\
\hline & & \multicolumn{2}{|c|}{ Uso residencial } & \multicolumn{2}{|r|}{36} \\
\hline \multicolumn{4}{|c|}{ Background Estação Ecológica do Taim ${ }^{19}$} & \multicolumn{2}{|c|}{0,03} \\
\hline
\end{tabular}

DP: desvio padrão; (prof.): profundidade de amostragem em $\mathrm{cm}$

A Figura 1 apresenta a distribuição vertical do mercúrio, desde a superfície até o nível do lençol freático em cada ponto amostrado. Observa-se que a variação vertical da concentração de $\mathrm{Hg}$ nos aterros é bastante irregular. Nos aterros mais antigos (pontos 1, 2 e 3 ) a concentração do mercúrio apresenta tendência de aumento com a profundidade, enquanto que no aterro mais recente (ponto 4) a tendência é ser mais alta nas camadas superficiais.

Os valores de concentração de $\mathrm{Pb}$ encontrados nas amostras analisadas variam de 46,0 a 570,8 mg kg-1 . A concentração de $\mathrm{Cu}$ varia de 9,5 a 718,0 $\mathrm{mg} \mathrm{kg}^{-1}$. A concentração de Zn está entre 91,6 a $2.378,0 \mathrm{mg} \mathrm{kg}^{-1}$ e a concentração de $\mathrm{Ni}$ varia de 5,0 a $51,0 \mathrm{mg} \mathrm{kg}^{-1}$ (Tabela 2). Observase tendência de aumento das concentrações de $\mathrm{Pb}, \mathrm{Cu}, \mathrm{Zn}$ e Ni com a diminuição da idade dos aterros, comportamento este contrário ao do $\mathrm{Hg}$, cujas concentrações tendem a ser maiores nos aterros mais antigos. Os resultados das análises das concentrações estão apresentados na Tabela 2.

Tabela 2. Concentração de $\mathrm{Pb}, \mathrm{Cu}, \mathrm{Zn}$ e Ni $\left(\mathrm{mg} \mathrm{kg}^{-1}\right)$ em aterros de Rio Grande

\begin{tabular}{|c|c|c|c|c|c|c|}
\hline Ponto & Descrição & $\begin{array}{l}\text { Data de } \\
\text { execução do } \\
\text { aterro }\end{array}$ & $\begin{array}{c}\mathrm{Pb} \\
\text { minimo } \\
\text { máximo } \\
\text { média } \\
\mathrm{DP}\end{array}$ & $\begin{array}{c}\mathrm{Cu} \\
\text { minimo } \\
\text { máximo } \\
\text { média } \\
\text { DP }\end{array}$ & $\begin{array}{c}\mathrm{Zn} \\
\text { minimo } \\
\text { máximo } \\
\text { média } \\
\text { DP }\end{array}$ & $\begin{array}{l}\mathrm{Ni} \\
\text { minimo } \\
\text { máximo } \\
\text { média } \\
\mathrm{DP} \\
\end{array}$ \\
\hline 1 & $\begin{array}{l}\text { Praça Sete } \\
\text { de Setembro }\end{array}$ & Séc. 18 & $\begin{array}{r}46,0 \\
\mathbf{2 9 4 , 3} \\
150,6 \\
105,6\end{array}$ & $\begin{array}{c}21,6 \\
\mathbf{1 3 7 , 9} \\
81,6 \\
45,5\end{array}$ & $\begin{array}{c}91,6 \\
\mathbf{3 0 6 , 6} \\
192,8 \\
81,6\end{array}$ & $\begin{array}{c}5,0 \\
\mathbf{1 0 , 6} \\
8,7 \\
1,9\end{array}$ \\
\hline 5 & $\begin{array}{c}\text { Praça Xavier } \\
\text { Ferreira }\end{array}$ & Séc. 19 início & $\begin{array}{c}75,3 \\
\mathbf{4 9 4 , 2} \\
234,3 \\
165,8\end{array}$ & $\begin{array}{c}49,0 \\
\mathbf{2 0 5 , 0} \\
108,7 \\
61,8\end{array}$ & $\begin{array}{l}126,3 \\
\mathbf{4 5 4 , 8} \\
278,8 \\
120,8\end{array}$ & $\begin{array}{c}12,8 \\
\mathbf{2 2 , 6} \\
16,0 \\
4,0\end{array}$ \\
\hline 8 & $\begin{array}{c}\text { Praça } \\
\text { Tamandaré }\end{array}$ & Séc. 19 final & $\begin{array}{c}50,7 \\
\mathbf{4 3 5 , 8} \\
285,9 \\
166,6\end{array}$ & $\begin{array}{c}9,5 \\
\mathbf{1 2 2 , 0} \\
74,8 \\
47,2\end{array}$ & $\begin{array}{c}103,1 \\
\mathbf{1 0 0 9 , 4} \\
705,6 \\
425,4\end{array}$ & $\begin{array}{c}15,6 \\
\mathbf{2 3 , 6} \\
18,8 \\
3,6\end{array}$ \\
\hline 9 & $\begin{array}{c}\text { Aterro } \\
\text { particular }\end{array}$ & Séc 20 final & $\begin{array}{l}194,7 \\
\mathbf{5 7 0 , 8} \\
353,0 \\
156,4\end{array}$ & $\begin{array}{l}216,0 \\
\mathbf{7 1 8 , 0} \\
420,1 \\
210,7\end{array}$ & $\begin{array}{c}289,3 \\
\mathbf{2 3 7 8 , 0} \\
1304,1 \\
936,6\end{array}$ & $\begin{array}{l}23,9 \\
\mathbf{5 1 , 0} \\
37,9 \\
10,6\end{array}$ \\
\hline \multicolumn{3}{|c|}{ Referência de qualidade Cetesb ${ }^{22}$} & 17 & 35 & 60 & 13 \\
\hline \multicolumn{3}{|c|}{ Background Est. Ecológica do Taim ${ }^{19}$} & 3,4 & 6,7 & 35,3 & 13,9 \\
\hline
\end{tabular}

A distribuição das concentrações de $\mathrm{Cu}, \mathrm{Pb}, \mathrm{Zn}$ e $\mathrm{Ni}$ ao longo do perfil vertical nos aterros é semelhante à do Hg (Figura 1). Esta afinidade também é atestada pelos elevados valores de coeficientes de 


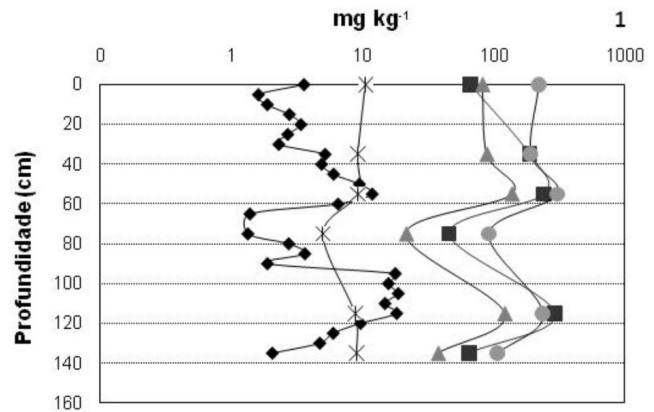

1
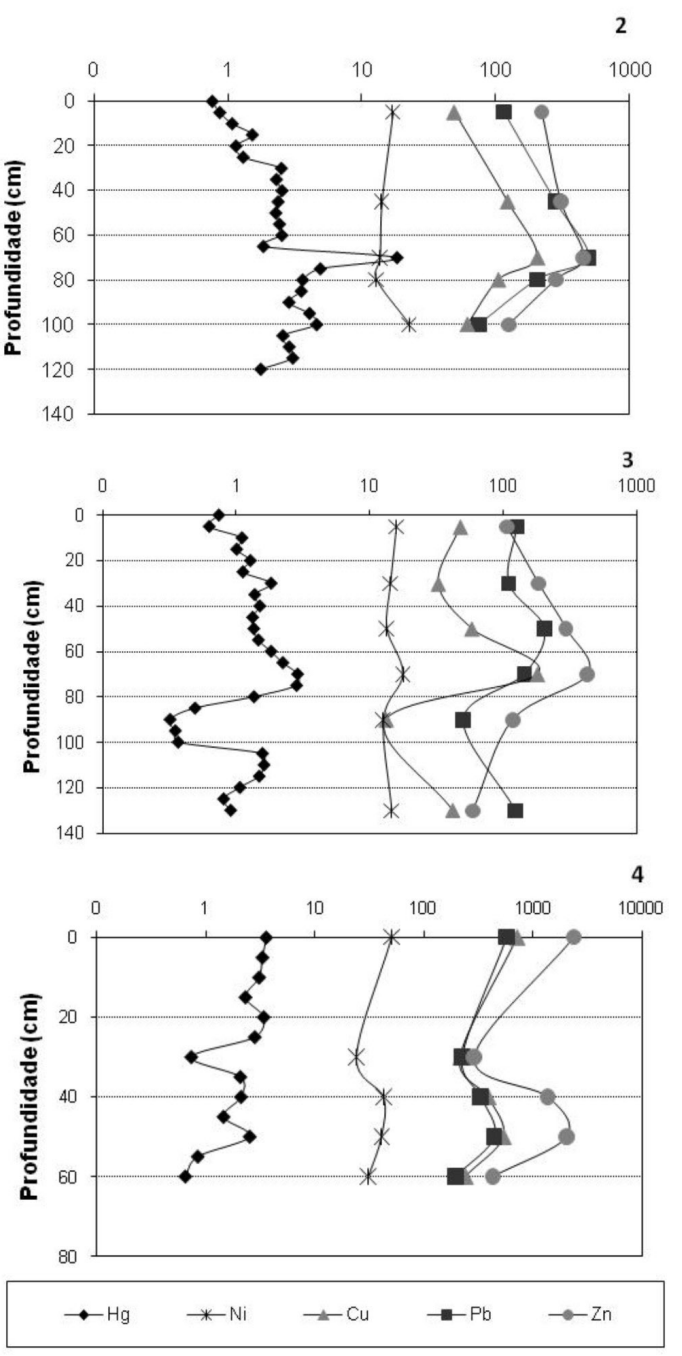

Figura 1. Distribuição vertical de $\mathrm{Hg}, \mathrm{Pb}, \mathrm{Cu}, \mathrm{Zn}$ e Ni nos pontos amostrados $(1,2,3$ e 4$)$

correlação entre Hg e os demais metais estudados (Tabela 3). Somente o Ni possui distribuição independente nos aterros antigos (pontos 1, 2 e 3 ), mas apresenta boa correlação com os outros metais no aterro recente.

\section{DISCUSSÃO}

As concentrações em solo superficial para áreas não contaminadas (background) dos metais estudados na região de Rio Grande foram obtidas por amostragem na Estação Ecológica do Taim, uma unidade de conservação administrada pelo Ibama, distante aproximadamente $70 \mathrm{~km}$ ao sul da cidade de Rio Grande. ${ }^{19}$ Os valores estão apresentados nas Tabelas 1 e 2 .

As concentrações de mercúrio verificadas nos aterros da cidade
Tabela 3. Coeficientes de correlação (r) entre concentrações de $\mathrm{Hg}$ com $\mathrm{Pb}$, $\mathrm{Cu}, \mathrm{Zn}$ e Ni no material dos aterros $(5 \mathrm{p}<0,001)$

\begin{tabular}{lccccc}
\hline Ponto & Local & $\mathrm{Pb}$ & $\mathrm{Cu}$ & $\mathrm{Zn}$ & $\mathrm{Ni}$ \\
\hline 1 & $\begin{array}{c}\text { Praça Sete } \\
\text { de Setembro }\end{array}$ & 0,94 & 0,84 & 0,72 & 0,23 \\
2 & $\begin{array}{c}\text { Praça Xavier } \\
\text { Ferreira }\end{array}$ & 0,99 & 0,96 & 0,70 & $-0,26$ \\
3 & Praça Tamandaré & 0,42 & 0,85 & 0,86 & 0,26 \\
4 & Aterro particular & 0,99 & 0,98 & 0,98 & 0,95 \\
\hline
\end{tabular}

de Rio Grande enquadram-se nos níveis de poluição moderados a altos, de acordo com a classificação proposta por Kot e Matyshkina. ${ }^{20}$ Estes autores estabelecem que solos com concentrações de mercúrio inferiores a $200 \mu \mathrm{g} \mathrm{kg}^{-1}$ possuem poluição baixa, entre $200 \mathrm{a} 2.000 \mu \mathrm{g}$ $\mathrm{kg}^{-1}$ a poluição é moderada e superior a $2.000 \mu \mathrm{g} \mathrm{kg}^{-1}$ é considerada alta. A Cetesb estabeleceu em 2001 como valor orientador o limite de $2,5 \mathrm{mg} \mathrm{kg}^{-1}$ de $\mathrm{Hg}$ para intervenção em solos de uso agrícola e $5,0 \mathrm{mg} \mathrm{kg}^{-1}$ de $\mathrm{Hg}$ para intervenção em solos de uso residencial, ${ }^{21}$ sendo que os valores máximos encontrados nos aterros da cidade de Rio Grande $\left(18,7 \mathrm{mg} \mathrm{kg}^{-1}\right)$ superam em mais de sete vezes e três vezes, respectivamente, estes valores. Em 2005 a Cetesb reviu os valores orientadores propostos para $\mathrm{Hg}$ em solos e, de forma a aumentar significativamente a permissividade, propôs os valores de $12 \mathrm{mg} \mathrm{kg}^{-1}$ para intervenção em solos com uso agrícola e $36 \mathrm{mg} \mathrm{kg}^{-1}$ para intervenção em solos sob uso residencial; ${ }^{22}$ segundo este novo critério, os valores máximos de $\mathrm{Hg}$ encontrados nos aterros de Rio Grande superam apenas o limite de intervenção para uso agrícola do solo. Em todos os casos, estas restrições apresentam implicações importantes, pois o entorno das praças apresenta uso residencial e parte do aterro particular é cultivada como horta comercial. Embora se observe a tendência de menores concentrações de $\mathrm{Hg}$ nas porções mais superficiais dos aterros no centro histórico de Rio Grande (pontos 1, 2 e 3), está presente algum risco gerado pelo consumo de alimentos produzidos em hortas domésticas com solos poluídos por mercúrio e situações cotidianas de geofagia voluntária entre crianças e animais. ${ }^{23}$ Em locais ventosos, como nas regiões litorâneas e, especialmente, na cidade de Rio Grande, a geofagia involuntária também pode se constituir em caminho potencial para a contaminação, através da ingestão continuada de material em suspensão.

Ao compararmos a poluição por mercúrio em Rio Grande com poluições urbanas conhecidas, foram relatadas, entre outras, contaminações acima de 2 ppm em solos urbanos de Middle Ammur, Rússia, vinculados a termelétricas e planta industrial de papel com tecnologia cloro-soda $;^{20}$ uma fábrica de termômetros de vidro com bulbo de mercúrio nos subúrbios de Varsóvia, Polônia, ocasionou poluição de até $200 \mathrm{mg} \mathrm{kg}^{-1} \mathrm{em}$ solos do entorno; ${ }^{24}$ métodos artesanais para refinar o zinco, com importantes liberações gasosas de mercúrio, eram utilizados na China desde o século 17 e contaminaram solos do entorno das fundições em até $0,9 \mathrm{mg} \mathrm{kg}^{-1}, 25$ uma técnica medieval de produção de feltro para chapéus na Idade Média empregava uma solução quente de nitrato de mercúrio (carroting) no tratamento das peles utilizadas como matéria-prima, ${ }^{3}$ sendo que esta atividade foi responsável pela poluição de muitos locais ao redor do mundo onde a produção de chapéus de feltro foi indústria importante durante os séculos 18 e 19 (Inglaterra, França, Itália), com destaque especial para as cidades de Danbury, Brookfield e Norwalk, Connecticut, nos Estados Unidos da América, que deixaram um legado de severa poluição observada em solos e sedimentos fluviais (até $60 \mathrm{mg} \mathrm{kg}^{-1}$ ). ${ }^{26-28}$

Observa-se que muitos destes sítios apresentam valores absolutos de poluição por mercúrio maiores do que aqueles encontrados na presente amostragem executada nos aterros da cidade de Rio Grande, no entanto, a poluição nesta se estende até profundidades da ordem 
de $140 \mathrm{~cm}$, enquanto que nos outros locais relatados a poluição é registrada principalmente em camadas superficiais de solos. Este condicionamento indica que a quantidade de $\mathrm{Hg}$ armazenada no subsolo da cidade de Rio Grande é expressiva e pode representar várias vezes os estoques deste elemento no sítio de Danbury e/ou Varsóvia, por exemplo. Além disto, o volume armazenado deste elemento no solo constitui significativa fonte de contaminação dos sedimentos do estuário da Lagoa dos Patos, o que foi confirmado em estudos anteriores. ${ }^{9,10}$ A dimensão da área atingida pela contaminação em Rio Grande leva a crer que nesta região estavam instaladas atividades produtivas artesanais e/ou industriais que utilizavam quantidades importantes de compostos de mercúrio em seus processos.

As concentrações de $\mathrm{Pb}, \mathrm{Cu}, \mathrm{Zn}$ e Ni também são elevadas, relativamente aos valores de referência de qualidade para solos propostos pela Cetesb. ${ }^{22}$ Os resultados das análises destes elementos estão apresentados na Tabela 2.

Elevadas concentrações de $\mathrm{Pb}, \mathrm{Cu}$ e $\mathrm{Zn}$ são comuns em ambientes em que ocorreram atividades que usavam as tecnologias conhecidas nos séculos 18 e 19, onde estavam entre os principais elementos metálicos disponíveis. ${ }^{3} \mathrm{O}$ chumbo foi amplamente utilizado em armas, munições, corantes e tubulações, entre outros. O Cu fazia parte das ligas empregadas em armamentos (como o bronze dos canhões), munição, utensílios de cozinha (inclusive pratos e panelas), nos botões e adornos em roupas (latão). O bronze é uma liga metálica contendo $90 \%$ de $\mathrm{Cu}$ e $10 \%$ de $\mathrm{Sn}$. O latão é uma liga que contém $67 \%$ de $\mathrm{Cu}$ e $33 \%$ de Zn. O zinco ocorre naturalmente em percentuais variáveis como impureza na paragênese dos sulfetos, que são os principais minerais de minério dos metais $\mathrm{Cu}$ e $\mathrm{Pb}$, e pode acompanhar este elementos quando os processos de separação e refinamento são rudimentares. As maiores concentrações de $\mathrm{Pb}, \mathrm{Cu}$ e $\mathrm{Zn}$ em aterros mais recentes podem ser entendidas como constatação de que as atividades que causaram estas poluições foram continuamente incrementadas ao longo do tempo, de acordo com o desenvolvimento da cidade. $\mathrm{O}$ Ni é metal de tecnologias mais modernas, onde os tratamentos de superfície são importantes e, posto que estas tecnologias só passaram a ser empregadas no século 20, este elemento apresenta correlação com os outros metais estudados apenas no aterro mais recente.

A distribuição vertical de $\mathrm{Hg}$ nos perfis estudados apresenta-se acentuadamente irregular, formando alguns picos com concentrações abruptamente elevadas, sugerindo que os aterros foram executados com material contaminado e a concentração de $\mathrm{Hg}$ em cada local depende da razão de mistura de material contaminado com areia inerte, abundante no entorno. As distribuições verticais de $\mathrm{Pb}, \mathrm{Cu}$ e $\mathrm{Zn}$ são semelhantes às do $\mathrm{Hg}$ (Figura 1), o que fortalece a hipótese de que as concentrações são autóctones, ou seja, as concentrações encontradas hoje são as mesmas e estão nos mesmos locais dos aterros em que foram lançadas. A presença de $\mathrm{Hg}$ em concentrações irregulares profundas nos aterros (que correspondiam ao nível da superfície do solo à época da sua execução), e sua estreita correlação com $\mathrm{Pb}, \mathrm{Cu}$ e $\mathrm{Zn}$ ao longo dos perfis (Tabela 3), testemunha a contemporaneidade da fonte de contaminação. O Ni mostra valores elevados de poluição e correlação com os outros metais estudados apenas no aterro recente, porque sua presença está ligada a atividades tecnológicas que se tornaram importantes ao longo do século 20 (indústrias químicas e do petróleo, metalmecânica, tratamento de superfícies, etc). ${ }^{29}$

A fonte de poluição por $\mathrm{Hg}$ em Rio Grande ainda é sujeita a questionamentos. Não foram, até agora, encontrados registros históricos que demonstrassem o tipo de produção e ocupação da população no século 18 com utilização de grandes quantidades de $\mathrm{Hg}$. A busca de dados históricos da época da construção do primeiro aterro poluído por mercúrio (1738) está substancialmente prejudicada devido aos registros da cidade de Rio Grande anteriores à invasão espanhola (1763-1776) terem sido destruídos quando daquela ocupação. No entanto, a circunstância de que as condições naturais da região compreendem banhados e terras baixas inundáveis, densamente povoadas por ratões do banhado e capivaras que, entre outros grupos animais, têm a pelagem adequada à produção de feltro de boa qualidade, fortalece a hipótese de que a produção de pelo e tratamento de peles foi a atividade que mais utilizou $\mathrm{Hg}$ em Rio Grande.

O processo medieval conhecido como carroting consistia no uso de solução de nitrato de $\mathrm{Hg}$ a quente para tratar peles para a produção de feltro de lã. ${ }^{3,26}$ Esta técnica possivelmente foi implementada em Rio Grande na primeira metade do século 18 para tratamento de peles de ratões do banhado, capivaras e gado, podendo ter sido realizada de forma artesanal em vários pontos da cidade antiga, o que explicaria a elevada poluição dos aterros e grande área de espalhamento. $\mathrm{Na}$ segunda metade do século 19 registrou-se crescimento das indústrias de feltro e os aterros deste período mostraram menores concentrações de $\mathrm{Hg},{ }^{29} \mathrm{o}$ que pode ser resultado da organização das fontes poluidoras artesanais em unidades industriais. A última empresa produtora de tapetes e feltro em funcionamento até a primeira metade do século XX, em Rio Grande, era a Indústria Rheingantz que, por imposição de legislação federal, parou de utilizar o nitrato de $\mathrm{Hg}$ na década de 1950 (nos EUA o processo de carroting foi proibido ainda na década de 1930), ${ }^{26}$ devido à contaminação dos trabalhadores. Estes fatos explicariam as concentrações menores de $\mathrm{Hg}$ nos aterros mais recentes de Rio Grande, em comparação com aterros mais antigos.

O centro histórico da cidade de Rio Grande, onde estão inseridas as três praças poluídas por $\mathrm{Hg}$, constitui-se numa área urbana consolidada, onde medidas de remediação (remoção de solo), usualmente empregadas em situações de poluição, não podem ser aplicadas. É provável que outras cidades brasileiras que possuíam, na mesma época, condições ambientais e atividades industriais similares às de Rio Grande, estejam submetidas a problemas de poluição semelhantes.

\section{CONCLUSÕES}

Os aterros onde estão inseridas as praças do centro histórico da cidade de Rio Grande estão poluídos por mercúrio.

A distribuição do $\mathrm{Hg}$ ao longo do perfil vertical dos aterros urbanos estudados e sua correlação com $\mathrm{Pb}, \mathrm{Cu}$ e $\mathrm{Zn}$ atestam a contemporaneidade das ações poluidoras com a construção dos aterros.

Ha indícios de que nos primeiros anos de sua história, durante o período colonial, a cidade de Rio Grande pode ter sido palco de atividades artesanais e industriais utilizadoras de $\mathrm{Hg}$, empregando técnicas de carroting para tratamento de peles e produção de peles, feltro, tapetes e chapéus.

Outras cidades localizadas ao longo da costa brasileira e que possuam características semelhantes àquelas de Rio Grande em relação ao meio físico, colonização, ocupação e desenvolvimento industrial, podem registrar níveis elevados de poluição por mercúrio, o que sustenta a recomendação de realizar estudos similares em pólos urbano-industriais contemporâneos com o mesmo condicionamento.

\section{MATERIAL SUPLEMENTAR}

Está disponível gratuitamente em http//quimicanova.sbq.org.br, na forma de arquivo PDF, com acesso livre, a Figura 1S, que apresenta mapa com a área atual ocupada pela cidade de Rio Grande, os pontos de coleta de amostras e a cronologia dos aterros de solo criado.

\section{REFERÊNCIAS}

1. Rossini, S. R. G.; Reimão, R.; Levévre, B. H.; Medrado-Faria, M. A.; Arquivos de Neuro-Psiquiatria 2000, 58, 32.

2. USEPA; Mercury Study Report to Congress, EPA-452/R-97-004, 1997. 
3. Baird, D. G.; Quimica ambiental, $2^{\mathrm{a}}$ ed., Editora Bookman: São Paulo, 2002, cap. 5.

4. Zhang, A.; Wong M. H.; Environment International 2007, 33, 108.

5. Knobeloch, L.; Anderson H.; Environ. Res. 2007, 13, 205.

6. Santos, E. C. O.; Jesus, I. M.; Brabo, E. S.; Fayal, K. F.; Sá Filho, G. C.; Lima, M. O.; Revista Brasileira de Epidemiologia 2003, 6, 171.

7. Pinheiro, M. C. N.; Nakanishi, J.; Oikawa, T.; Guimarães, G.; Quaresma, M.; Cardoso, B.; Amoras, W. W.; Harada, M.; Magno, C.; Vieira, J. L. F.; Xavier, M. B.; Bacelar, D. R.; Revista da Sociedade Brasileira de Medicina Tropical 2000, 33, 265.

8. Mirlean, N.; Baraj, B.; Niencheski, L. F.; Baisch, P.; Robinson, D.; Mar. Pollut. Bull. 2001, 42, 1114.

9. Marins,R. V.; Paula Filho, F. J.; Maia, S. R. R.; Lacerda, L. D.; Marques, W. S.; Quim. Nova 2004, 27, 5.

10. Mirlean, N.; Oliveira, C.; Journal of Coastal Research 2006, 22, 1573.

11. Instituto Brasileiro de Geografia e Estatística; Pesquisa Nacional por Amostra de Domicílios, Brasil, 2007.

12. Alves, F. N.; Torres, L. H.; A cidade do Rio Grande: uma abordagem historico-historiográfica, Ed. da FURG: Rio Grande, 1997.

13. Alves F. N.; Torres L. H.; A cidade do Rio Grande: estudos históricos, Universidade de Rio Grande e Secretaria Municipal de Educação e Cultura: Rio Grande, 1995.

14. Motuzova G. V.; Methods of chemical monitoring of soil cover, Moscow University: Moscow, 1988.

15. United States Environmental Protection Agency - U.S. EPA; Method 7471. Digestion of Solids and Semi-solids for Mercury, EUA, 1986. (CA 7439-97-6).

16. United States Environmental Protection Agency - U.S. EPA; Method 3050b. Acid Digestion of Sediments, Sludges and Soils, EUA, 1996.
17. Wehry, E. Em Handbook of Instrumental Techniques of Analytical Chemistry; Settle, F., ed.; Prentice Hall: Upper Saddle River, 1997.

18. National Research Council Canada; HISS-1, MESS-3, PACS-2 Marine Sediment Reference Material for Trace Metals and other Constituents, NRCC, 2004.

19. Conceição, C. O.; Dissertação de Mestrado, Fundação Universidade de Rio Grande, Brasil, 2005.

20. Kot, F. S.; Matyushkina, A. L.; J. Environ. Monit. 2002, 4, 803.

21. Companhia de Tecnologia de Saneamento Ambiental - CETESB; Relatório de Estabelecimento de Valores Orientadores para Solos e Águas Subterrâneas, São Paulo, 2001.

22. Companhia de Tecnologia de Saneamento Ambiental - CETESB; Decisão de Diretoria ${ }^{\circ}$ 195-2005-E, São Paulo, 2005.

23. http://www.cprm.gov.br/publique/media/geo_med1.pdf, acessada em Outubro 2009

24. Bozke, L.; Kowalski, A.; Astel, A.; Baranski, A.; Gworek, B.; Siepak, J.; Environ. Geo. 2008, 55, 1075.

25. Feng, X.; Li, G.; Qiu, G.; Sci. Total Environ. 2006, 1, 47

26. Varekamp, J. C.; Chin. J. Geochem. 2006, 25, 236.

27. Jallow, B.; Welch, P.; Goldoff, B.; Varekamp, J.; $38^{\text {th }}$ Annual Meeting, The Geological Society of America, Halifax, EUA, 2003, http://gsa. confex.com/gsa/2003NE/finalprogram/abstract_51250.htm, acessada em Março 2010.

28. Varekamp, J. C.; Kreulen, B.; Buchholtz M. R.; Mecray, E. L.; Environmental Geology 2003, 43, 268.

29. Martins, S. F.; Cidade do Rio Grande: industrialização e urbanidade (1873-1990), Ed. da FURG: Rio Grande, 2006. 


\section{POLUIÇÃO POR MERCÚRIO EM ATERROS URBANOS DO PERÍODO COLONIAL NO EXTREMO SUL DO BRASIL}

Luiz Paulo de Moura Fragomeni* e Ari Roisenberg

Instituto de Geociências, Universidade Federal do Rio Grande do Sul, CP 15001, 91501-970 Porto Alegre - RS, Brasil Nicolai Mirlean

Instituto de Oceanografia, Fundação Universidade de Rio Grande, CP 474, 96200-900 Rio Grande - RS, Brasil

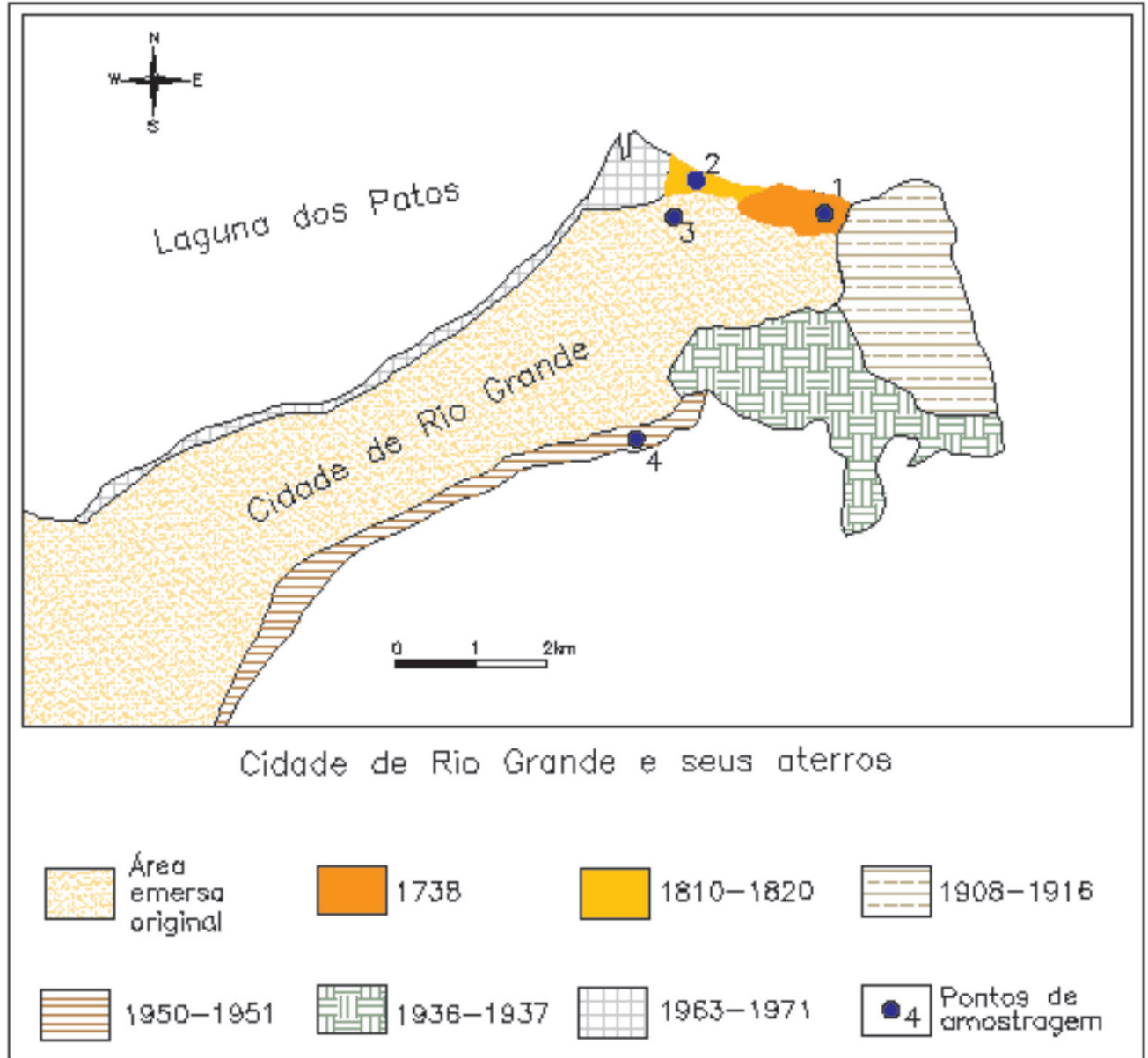

Figura 1S. A área atual ocupada pela cidade de Rio Grande, os pontos de coleta de amostras e a cronologia dos aterros de solo criado. Adaptada da ref. 10 